\title{
Impairment of IGF2 gene expression in prostate cancer is triggered by epigenetic dysregulation of IGF2-DMRO and its interaction with KLF4
}

Undraga Schagdarsurengin ${ }^{1,2}$, Angela Lammert ${ }^{3}$, Natalie Schunk ${ }^{1}$, Diana Sheridan ${ }^{4}$, Stefan Gattenloehner ${ }^{4}$, Klaus Steger ${ }^{1,5}$, Florian Wagenlehner ${ }^{1}$ and Temuujin Dansranjavin ${ }^{1 *}$

\begin{abstract}
Background: Human cancer cells often exhibit impaired IGF2 expression and the underlying mechanisms are multifaceted and complex. Besides the well-known imprinting control region /GF2/H19-ICR, the involvement of a differentially methylated region in the promoter PO of IGF2 gene (IGF2-DMRO) has been suggested. Here, we evaluate several mechanisms potentially leading to up- and/or down-regulation of IGF2 expression in prostate cancer and present a novel role of Kruppel-like factor 4 (KLF4) as a transcriptional regulator of IGF2 binding in IGF2-DMRO.

Methods: Putative binding sites for transcription factors were identified in IGF2-DMRO using JASPAR CORE database. Gene expressions were analyzed by RT-qPCR in prostate carcinoma and adjacent benign prostate hyperplasia samples obtained by radical prostatectomy (86 RP-PCa and 47 RP-BPH) and BPH obtained by transurethral prostate resection (13 TUR-BPH). Pyrosequencing and qMSP were used for DNA methylation studies in IGF2-DMRO, IGF2/H19-ICR and Glutathione-S-transferase-P1 (GSTP1) promoter. Loss of imprinting (LOI) was analyzed by RFLP. Copy number variation (CNV) test was performed using qBiomarker CNV PCR Assay. KLF4-binding and histone-modifications were analyzed by ChIP-qPCR in prostate cancer cell lines exhibiting differentially methylated IGF2-DMRO (LNCaP hypomethylated and DU145 hypermethylated). KLF4 protein was analyzed by western blot. Statistical associations of gene expression to methylation, IGF2 LOI and CNV were calculated by Mann-Whitney-U-test. Correlations between gene expression and methylation levels were evaluated by Spearman's-Rank-Correlation-test.

Results: We found a significant reduction of IGF2 expression in the majority of RP-PCa and RP-BPH in comparison to TUR-BPH. Analyzing potential molecular reasons, we found in RP-PCa and RP-BPH in comparison to TUR-BPH a significant hypomethylation of IGF2-DMRO, which coincided with hypermethylation of GSTP1-promoter, a prominent marker of prostate tumors. In contrast, IGF2 LOI and CNV did not associate significantly with up- and/or down-regulation of IGF2 expression in prostate tumors. By analyzing IGF2-DMRO, we detected a consensus sequence for KLF4 with a z-score of 7.6. Interestingly, we found that KLF4 binds to hypomethylated (17\%) IGF2-DMR0 enriched with H3K9me3 and H3K27me3 (LNCaP), but does not bind under hypermethylated (85\%) and H3K4me3-enriched conditions (DU145). KLF4 expression was detected in TUR-BPH as well as in RP-BPH and RP-PCa and showed a highly significant correlation to IGF2 expression.

(Continued on next page)
\end{abstract}

\footnotetext{
* Correspondence: temuujin.dansranjavin@chiru.med.uni-giessen.de

${ }^{1}$ Clinic of Urology, Pediatric Urology and Andrology, Justus-Liebig-University

Giessen, Rudolf-Buchheim-Str. 7, 35392 Giessen, Germany

Full list of author information is available at the end of the article
} 
(Continued from previous page)

Conclusions: Our study demonstrated that in human prostate cancer the impairment of IGF2 expression is accompanied by hypomethylation of IGF2-DMRO. We revealed that KLF4 is a putative transcriptional regulator of IGF2, which binds in IGF2-DMRO in dependence of the prevailing epigenetic state in this region. Herewith we provide complementary new insights into IGF2 dysregulation mechanisms as a critical process in prostate tumorigenesis.

Keywords: IGF2, IGF2-DMRO, KLF4, Transcription regulation, Prostate cancer

\section{Background}

The insulin-like growth factor 2 (IGF2) is a member of the IGF/insulin signaling pathway and regulates, together with IGF1 and insulin, the cell proliferation and differentiation during embryonic and post-natal development [1-3]. IGF2, which possesses anti-apoptotic as well as mitogenic capacities, is widely expressed lifelong and is involved in regulation of growth [4, 5]. In prostate, IGF2 plays an important role as a paracrine and autocrine regulator of cell growth and was found to be expressed in prostate epithelial cells and in prostate tumor associated stromal cells [6-9].

The expression of the IGF2 gene is parentally imprinted. In most human cells, IGF2 expression is restricted to the paternal allele, whereas the maternal allele is repressed [10]. The strict imprinting control is thought to be realized by epigenetic modifications, such as DNA methylation and post-translational histone modifications (PTHMs) at specific loci along the IGF2 and $H 19$ gene cluster. The so called imprinting control region (IGF2/H19-ICR), which contains a CTCF binding site, is located at the boundary between the IGF2 and $H 19$ genes. At normal state, IGF2/H19-ICR is methylated in the paternal allele and unmethylated in the maternal allele [10]. In human cancer diseases, IGF2 is often epigenetically dysregulated. Loss of imprinting (LOI) of IGF2, aberrant methylation in IGF2/H19-ICR and up- or down-regulation of IGF2 expression, respectively, have been shown to be associated with a number of human tumors including colorectal, breast, liver, bladder, Wilms, ovarian, esophageal, prostate tumors and osteosarcoma [11-21].

In addition to IGF2/H19-ICR, it is supposed that a differential methylated region P0 upstream of exon 2 (IGF2-DMR0) possesses promoter activities, has a defined methylation status in normal cells (methylated in the paternal and unmethylated in the maternal allele) and a considerable capacity to regulate IGF2 expression $[19,22,23]$. Numerous studies provide evidence that hypomethylation of the IGF2-DMR0 might be also a potent reason for IGF2 LOI as well as for aberrant IGF2 expression, and thus, a predictive factor for cancer development [19, 22-26]. In particular, in prostate cancer, it was observed that hypomethylation of IGF2DMR0 correlates with decreased IGF2 expression [20].
Moreover, a marked IGF2 LOI was found in adjacent tumor-associated tissues as well as in tumor-free distant regions indicating that IGF2 dysregulation could be an early initiation factor in development of prostate neoplasia [20]. However, the interrelation between methylation changes in IGF2-DMR0, LOI and aberrant IGF2 expression in human and, in particular prostate cancer, is still inconsistent and not clear. The available data were generated in different cells and tumors and are mutually contradictory. Therefore, additional insights with regard to co-factors involved in regulation of IGF2-DMR0 and IGF2 imprinting are needed to elucidate and understand the mechanisms of IGF2 dysregulation during carcinogenesis.

A number of transcription factor families, especially the family of Kruppel-like factors (KLFs), are capable to bind to G/C-rich DNA sequences [27]. One of the members, KLF4, is expressed in a wide variety of tissues including gut, thymus, cardiac myocytes and lymphocytes, and plays an important role in cell proliferation, stem cell self-renewal and maintenance of normal tissue homeostasis [28]. Several studies described and emphasized the role of KLF4 in human cancer and its function in the context of cell and tissue specificity [29-31]. According to previous studies, KLF4 is able to act as a potent tumor suppressor gene in colon and lung carcinogenesis $[32,33]$ as well as an oncogene that has been shown in breast and skin squamous cell carcinoma $[34,35]$. In human prostate, a differential KLF4 gene expression was observed when comparing normal, hyperplastic and cancerous tissues [36, 37], whereas at protein level KLF4 was detected in a large majority of epithelial prostatic cells, irrespective of malignant transformation [37]. A recent study demonstrated that in prostate cancer cell lines PC3 and LNCaP, KLF4 is associated with the proliferative activity of cells via the KLF4-KRT6/13 pathway [38].

Our current research addressed potential mechanisms leading to IGF2 dysregulation in prostate carcinogenesis and emphasized the role of KLF4 in regulation of IGF2-DMR0. Utilizing prostate cancer cell lines LNCaP and DU145, we demonstrated that KLF4 binds to hypomethylated IGF2-DMR0 and affects IGF2 expression in dependence to prevailing post-translational histone modifications. Analyzing prostate tissues samples from patients with malignant and benign prostate enlargements, we 
found a highly significant correlation between IGF2 and KLF4 expression. Methylation status of IGF2-DMR0, but not of IGF2/H19-ICR, was associated with PCa and adjacent $\mathrm{BPH}$. Our results reveal that the transcription factor KLF4 is a potent co-factor involved in impairment of IGF2 expression during prostate carcinogenesis.

\section{Methods}

\section{Patient samples}

Tissue samples from 86 RP-PCa (prostate carcinoma samples obtained by radical prostatectomy; patients' median age 67, range 52-76), 47 RP-BPH (benign prostate hyperplasia samples adjacent to $\mathrm{PCa}$ obtained by radical prostatectomy; patients' median age 69, range 52-75) and 13 TUR-BPH (benign prostatic hyperplasia samples obtained by transurethral resections of the prostate; patients' median age 73, range 57-88) were collected at the Department of Urology, Pediatric Urology and Andrology, Justus-Liebig-University (JLU) Giessen, Germany. All patients gave their written informed consent and the study was approved by the ethical committee of the Medical Faculty, JLU Giessen (ethical vote, AZ123/12). Prostate tissue samples were characterized at the Institute of Pathology, JLU Giessen. All clinical and pathological data of analyzed patients are summarized in Table 1. RP-PCa tissue samples with at least $60 \%$ of tumor cell amount were selected for this study. Due to technical failures and restricted tumor material not every experiment could be evaluated for the whole number of samples. The

Table 1 Summary of clinical and pathological parameters of analyzed patients, who underwent radical prostatectomy (RP) or transurethral resection (TUR) of the prostate

\begin{tabular}{|c|c|c|c|c|}
\hline $\begin{array}{l}\text { Clinical and Pathological } \\
\text { Parameters }\end{array}$ & Specifications & $\begin{array}{l}\text { RP-PCa } \\
n=86\end{array}$ & $\begin{array}{l}\text { RP-BPH } \\
n=47\end{array}$ & $\begin{array}{l}\text { TUR-BPH } \\
n=13\end{array}$ \\
\hline Age at diagnosis & Median (min-max) & $67(54-76)$ & $69(52-75)$ & $73(57-88)$ \\
\hline \multirow[t]{3}{*}{ Lymph node metastasis } & No (absent), $\mathrm{n}$ & 63 & 24 & $n / a$ \\
\hline & $\mathrm{N} 1$ (present), n & 7 & 3 & $\mathrm{n} / \mathrm{a}$ \\
\hline & NX (unknown), n & 16 & 20 & $\mathrm{n} / \mathrm{a}$ \\
\hline \multirow{4}{*}{$\begin{array}{l}\text { Prostate specific } \\
\text { antigen (preoperative } \\
\text { level in } \mathrm{ng} / \mathrm{ml} \text { ) }\end{array}$} & $"<10 ", \mathrm{n}$ & 17 & 9 & $n / a$ \\
\hline & "10-15", n & 44 & 14 & $n / a$ \\
\hline & $">15 ", n$ & 25 & 13 & $\mathrm{n} / \mathrm{a}$ \\
\hline & Not known, $\mathrm{n}$ & - & 11 & $n / a$ \\
\hline \multirow[t]{3}{*}{ Pathological status } & T2a-T2c, n & 43 & 15 & $n / a$ \\
\hline & T3a-T3b, n & 36 & 11 & $n / a$ \\
\hline & $\mathrm{T} 4, \mathrm{n}$ & 7 & 3 & $n / a$ \\
\hline \multirow[t]{2}{*}{ Gleason score } & $" \leq 7 ", n$ & 63 & 32 & $\mathrm{n} / \mathrm{a}$ \\
\hline & $">7 ", n$ & 24 & 15 & $n / a$ \\
\hline
\end{tabular}

Abbreviations: $R P-P C a$ prostate carcinoma obtained by radical prostatectomy, $R P-B P H$ benign prostate hyperplasia adjacent to $P C a$ obtained by radical prostatectomy, TUR-BPH benign prostate hyperplasia obtained by transurethral resection, $n / a$ not applicable numbers of considered samples are given for each experiment in corresponding figures.

\section{Cell lines and culture conditions}

Human prostate cancer cell lines LNCaP, DU145 and PC3 were obtained from the German Resource Centre for Biological Material (Braunschweig, Germany) and cultured in RPMI-1640 medium (Invitrogen) supplemented with $10 \%$ fetal bovine serum (Invitrogen) and 1\% Penicillin-Streptomycin solution (Sigma Aldrich). The effect of the DNA methylation inhibitor 5-aza-2'deoxycytidine (5-aza-CdR, inhibitor of DNA methyltransferase 1) on IGF2 gene expression was analyzed in LNCaP (17\% hypomethylated in IGF2-DMR0) and DU145 (85\% hypermethylated in IGF2-DMR0) cell lines. Therefore, $2 \times 10^{6}$ cells were cultured for 3 days in the presence of $5 \mu \mathrm{M}$ 5-aza-CdR (Sigma Aldrich). The cells were harvested on the fourth day and utilized for DNA, RNA, protein and chromatin extractions.

\section{DNA extraction, pyrosequencing and qMSP}

DNA from tissue samples and cell lines was isolated by standard phenol/chloroform procedure. DNA was precipitated with $1 / 10$ volume $\mathrm{NaAc}(3 \mathrm{M})$ and 2.5 volume absolute ethanol. For deamination of unmethylated cytosines, $2 \mu \mathrm{g}$ DNA were denatured by sodium hydroxide $(3 \mathrm{M})$ and incubated with sodium bisulfite $(3.6 \mathrm{M})$ for $6 \mathrm{~h}$ at $56{ }^{\circ} \mathrm{C}$. Bisulfite-treated DNA was purified with Wizard DNA clean-up System (Promega). DNA methylation in IGF2-DMR0 and IGF2/H19-ICR (Fig. 1) was analyzed by pyrosequencing using primer sets listed in Table 2. Each pyrosequencing procedure included control DNAs (completely methylated and unmethylated EpiTect-control-DNAs (Qiagen). Methylation levels were calculated in percentage by PyroMark Q24 software 2.0 (Qiagen) and depicted in programs. DNA methylation levels show the percentage of cells possessing a complete methylation in an analyzed DNA region. A significant gain or loss of the number of cells possessing a complete methylation in the analyzed DNA region was considered as hyper- and hypomethylation, respectively.

GSTP1 promoter methylation was analyzed by quantitative methylation specific PCR (qMSP) using published primer sets [39] for amplification of unmethylated and methylated DNA in GSTP1 promoter (Table 2). Epi-Tectcontrol-DNAs (Qiagen) representing 100\% methylated and $100 \%$ unmethylated DNA were used as calibrators for evaluation of the methylation degree. Methylation independent primers binding in $\beta$-Actin gene (PCR product size $133 \mathrm{bp}$; forward primer: 5'-TGGTGATGGAGGAG GTTTAGTAAGT-3', revers primer: 5' - AACCAATAAA ACСТАСТССТСССТТАA-3',) were used as control primers for input DNA. Relative levels of unmethylated 


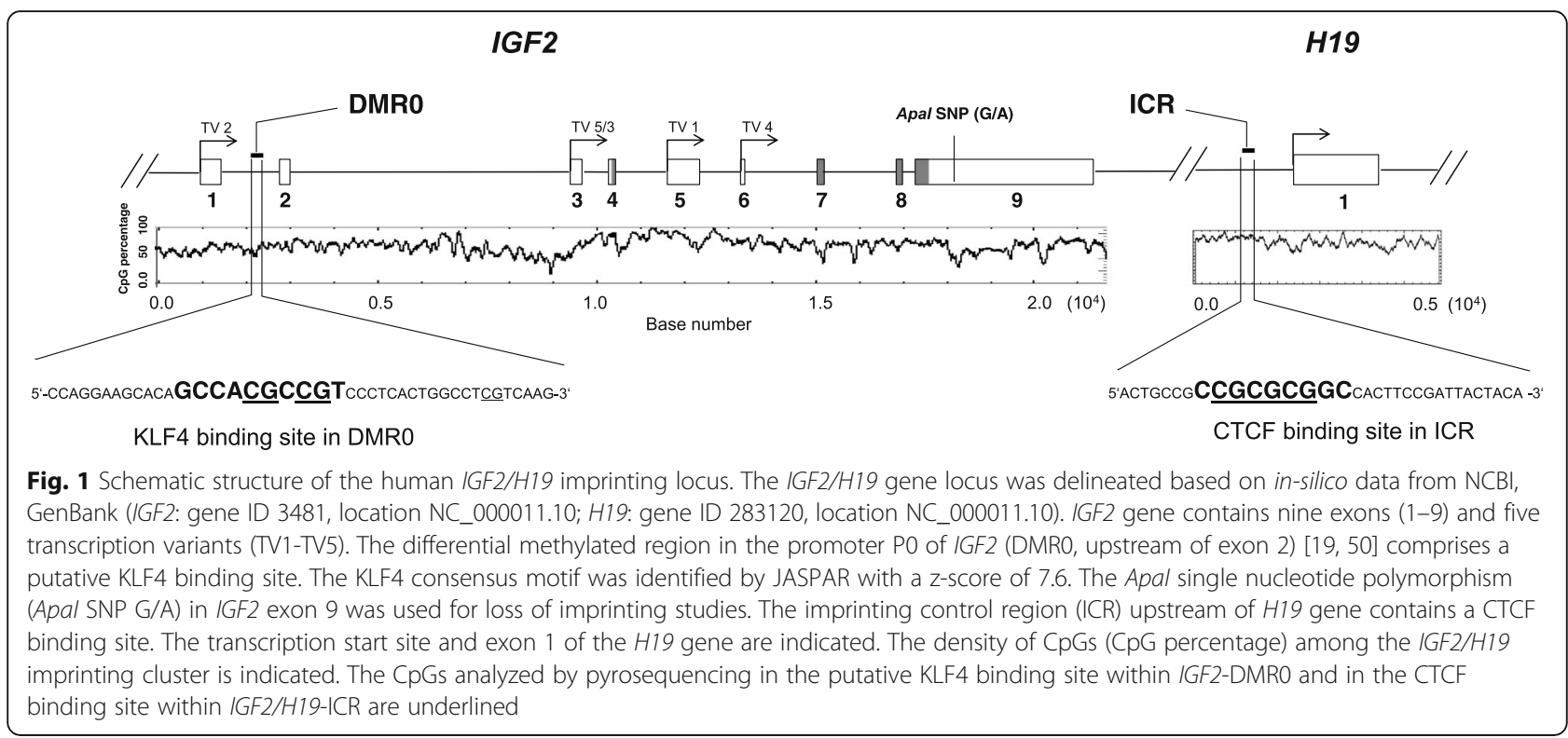

(RU) and methylated DNA (RM) in GSTP1 promoter were calculated using $2^{-\Delta \Delta C t}$ quantification method. The relative degree of GSTP1 methylation was calculated in percentage by formula $(\mathrm{RM} / \mathrm{RU}+\mathrm{RM}) \times 100$.

\section{RNA extraction and RT-qPCR}

Total RNA from prostate cancer cell lines and tissue samples was extracted using RNAeasy Mini Kit according to manufacturer's instruction (Qiagen). The cDNA was generated for each sample using $2 \mu \mathrm{g}$ RNA and Omniscript Reverse-Transcription (RT) System (Qiagen). Quantitative PCR (qPCR) was performed subsequently using iQ-SYBR-Green-Supermix (BioRad). All RT-qPCR primer sets and PCR product sizes for analyzed genes IGF2, KLF4, AMACR and $\beta$-Actin are listed in Table 2. Relative gene expression levels were calculated using 2 $-\Delta \Delta \mathrm{Ct}$ quantitation method by normalization to $\beta$-Actin (GenEx software, Multid Analyses AB). All PCR amplifications were carried out in triplicates and mean values were calculated.

\section{Analysis of IGF2 loss of imprinting (LOI)}

IGF2 LOI (bi-allelic expression) was analyzed using a known IGF2 single nucleotide polymorphism (SNP) G/A in exon 9 [18] (Fig. 1). In order to select heterozygous genotypes, restriction fragment length polymorphism (RFLP) method was performed on DNA samples isolated from prostate tumor tissues using PCR primers shown in Table 2 and the restriction enzyme ApaI (recognition site $\mathrm{GGGCC}^{\wedge} \mathrm{C}$ ). The cDNAs (mRNA reverse transcribed in copy DNA) from selected heterozygous samples were generated, and a RFLP analysis was performed using the same PCR primers (Table 2) and enzyme ApaI. The bi-allelic expression of IGF2 was evaluated on
cDNA after the separation of ApaI-restriction products on $2 \%$ agarose gel.

\section{Analysis of IGF2 copy number variation (CNV)}

The CNV of IGF2 gene was analyzed using the qBiomarker CNV PCR Assay for Human chromosome 11 tile 10,752 (Qiagen). This assay is based on amplification and quantification of an IGF2 sequence in relation to two reference genes ZNF80 and GPR15 [40]. Quantitative PCR reactions were performed according to manufacturer's protocol in triplicates in $20 \mu \mathrm{l}$ reaction volume containing Rotor-Gene Sybr Green PCR Master Mix (Qiagen). Data generated by qPCR were analyzed using the commercially available qBaseplus software (Biogazelle NV, Zwijnaarde, Belgium). The reference genes ZNF80 and GPR15 were used for normalization of the relative $\mathrm{CNV}$ values. Three blood DNA samples from healthy donors, assumed to have normal diploid genomes, were used as additional calibrators for calculation of CNV in different PCR runs. A minimum 2-fold increase of IGF2 copy numbers in comparison to blood DNA samples was determined as a "gain", and a decrease of IGF2 copy numbers (less than 0.5-fold) was determined as a "loss". Values similar to those in blood DNA samples were considered as "normal".

\section{Chromatin immunoprecipitation followed by qPCR (ChIP-qPCR)}

LNCaP and DU145 cells $\left(1 \times 10^{7}\right.$ cells $)$ were fixed with $1 \%$ formaldehyde for $10 \mathrm{~min}$ before quenching with glycine $(0.125 \mathrm{M})$ for $5 \mathrm{~min}$. The nuclei were isolated using nuclear isolation buffer $(150 \mathrm{mM} \mathrm{NaCl}, 10 \mathrm{mM}$ HEPES pH 7.5, $1.5 \mathrm{mM} \mathrm{MgCl}_{2}, 10 \mathrm{mM} \mathrm{KCl}, 0.5 \%$ Nonidet $\mathrm{P}-40$ and $0.5 \mathrm{mM}$ dithiothreitol) and resuspended in nuclear lysis buffer (50 mM Tris-Cl pH 8.1, 10 mM EDTA 
Table 2 Primer sets used for pyrosequencing, qMSP, RT-qPCR, ChIP-qPCR and for LOI and CNV studies

\begin{tabular}{|c|c|c|c|}
\hline Assay & Primer identity & Primer sequence $\left(5^{\prime}-3^{\prime}\right)$ & PCR-size (bp) \\
\hline \multirow[t]{6}{*}{ Pyro-sequencing } & IGF2-DMRO-PS-F & TाTाTGTTGTATITGGATTTAGATTTTT & 186 \\
\hline & IGF2-DMRO-PS-R & СTCCAAACACCCCCACCTTAA & \\
\hline & IGF2-DMRO-Seq & GTGGGGAGGGGGTTTATTIT & \\
\hline & IGF2-H19-ICR-PS-F & GGGGGCTCTTGCATAGCACATGGGTA & 242 \\
\hline & IGF2-H19-ICR-PS-R & ATAAACCCTTATCCTATAAATACCCTCA & \\
\hline & IGF2-H19-ICR-PS-Seq & GGTATTITTGGAGGTTITTIT & \\
\hline \multirow[t]{4}{*}{ qMSP } & GSTP1-MSP-U-F & GATGTTTGGGGTGTAGTGGTTGTT & 91 \\
\hline & GSTP1-MSP-U-R & CCACCCCAATACTAAATCACAACA & \\
\hline & GSTP1-MSP-M-F & TTCGGGGTGTAGCGGTCGTC & 97 \\
\hline & GSTP1-MSP-M-R & GCCCCAATACTAAATCACGACG & \\
\hline \multirow[t]{8}{*}{ RT-qPCR } & IGF2-RTPCR-F & GGGCAAGTTCTTCCAATATGA & 214 \\
\hline & IGF2-RTPCR-R & TCACTTCCGATTGCTGGC & \\
\hline & BActin-RTPCR-F & CGGAGTACTTGCGCTCAGGAGGA & 226 \\
\hline & BActin-RTPCR-R & CCTTCCTTCCTGGGAATGGAGTC & \\
\hline & KLF4-RTPCR-F & ACTCGCCTTGCTGATTGTCT & 127 \\
\hline & KLF4-RTPCR-R & AATTGGCCGAGATCCTTCTT & \\
\hline & AMACR-RTPCR-F & ACGACTTACAGGACAGCAGA & 181 \\
\hline & AMACR-RTPCR-R & СCTTCGTCTTCTCTGCAAAT & \\
\hline \multirow[t]{2}{*}{ ChIP-qPCR } & IGF2-DMRO-ChIP-F & CACCCTGGGGCCAAGGCAGT & 100 \\
\hline & IGF2-DMRO-ChIP-R & CTTGAGGGGTCATGGCACGGAAT & \\
\hline \multirow[t]{2}{*}{ LOI study } & IGF2-LOI-Apal-F & САССССССТСТTСТТТTСТ & 245 \\
\hline & IGF2-LOI-Apal-R & TACTGGGTCCCTCTGACTGCT & \\
\hline \multirow[t]{4}{*}{ CNV study } & ZNF80-GCN-F & CTGTGACCTGCAGCTCATCCT & 120 \\
\hline & ZNF80-GCN-R & TAAGTTCTCTGACGTTGACTGATGTG & \\
\hline & GPR15-GCN-F & GGTCCCTGGTGGCCTTAATT & 101 \\
\hline & GPR15-GCN-R & TTGCTGGTAATGGGCACACA & \\
\hline
\end{tabular}

Abbreviations: $q M S P$ quantitative methylation specific $P C R, R T-q P C R$ reverse transcription of RNA in cDNA followed by quantitative real-time PCR, ChIP- $q P C R$ chromatin immunoprecipitation followed by quantitative real-time PCR, IGF2-DMR0 differential methylated region in promoter P0 of the insulin-like growth factor 2 gene, IGF2/ H19-ICR imprinting control region of IGF2 and H19 genes, KLF4 Kruppel-like factor 4, AMACR Alpha-methylacyl-CoA racemase, LOI loss of imprinting, CNV copy number variation, $b p$-base pairs

and $1 \%$ SDS). Nucleic lysates were sonicated in order to get DNA fragments ranging from $200 \mathrm{bp}$ to $600 \mathrm{bp}$. The input DNA controls (10\%) were frozen after sonication until further processing. After blocking of unspecific DNA with salmon sperm DNA for 1 hour at $4{ }^{\circ} \mathrm{C}$, the sonicated nuclear material was immunoprecipitated using specific histone antibodies (anti-H3K27me3, -H3K9me3, and H3K4me3 from Abcam, and anti-KLF4 from R\&D Systems) by adding the protein A-conjugated Sepharose (Amersham Biosciences and GE Biosciences). One sample per cell line was incubated without antibodies and used as negative control. After immunoprecipitation over night at $4{ }^{\circ} \mathrm{C}$, protein-DNA complexes bound to Sepharose were washed, and the DNA was isolated according to standard ChIP procedure (Abcam). Enrichment of specific posttranslational histone modifications and of KLF4 in IGF2-
DMR0 was analyzed by qPCR with IGF2-DMR0 specific primers (Table 2). Input DNA was used as calibrator.

\section{Western blot analysis}

Whole lysates from LNCaP and DU145 cells $\left(1 \times 10^{7}\right.$ cells) were analyzed for KLF4 expression by western blot. Therefore, cells were washed with ice-cold PBS and scraped on ice after addition of $100 \mu \mathrm{L}$ RIPA buffer (Sigma Aldrich). Lysed cells were centrifuged at $13.000 \mathrm{rpm}$ for $30 \mathrm{~min}$ to precipitate cell debris, and the protein concentrations were measured in the supernatant with Pierce BCA Protein Kit (Thermo Fisher Scientific). Cell lysates (40 $\mu \mathrm{g}$ protein) were mixed with Laemmli buffer containing 10\% $\beta$-mercaptoethanol, cooked at $100{ }^{\circ} \mathrm{C}$ for $5 \mathrm{~min}$ and separated in SDS-PAGE. After the protein transfer to a polyvinylidene difluoride 
membrane, membranes were blocked with 5\% BSA and successively incubated with KLF4- (R\&D Systems, 1:500) and rabbit IgG HRP-antibody (GeneTex, 1:10,000). Chemiluminescence was measured after addition of Pierce ECL Western Blotting Substrate (Thermo Fisher Scientific).

\section{Statistical analysis}

Non parametric Mann-Whitney $U$ test was used for assessment of statistical differences between the analyzed groups (TUR-BPH, RP-BPH and RP-PCa; LOI and MOI; CNV-gain, -loss and -normal) regarding the methylation levels of IGF2-DMR0, IGF2/H19-ICR and GSTP1 promoter as well as for comparison of gene expression levels for IGF2, KLF4 and AMACR (normalized to $\beta$ Actin). Spearman's rank correlation test was used for correlation of IGF2-DMR0 and IGF2/H19-ICR- to GSTP1-methylation levels and for correlation of KLF4 to IGF2 gene expression. Data represent median and range ( $\min$ to $\max$ ). $P<0.05$ was considered to be statistically significant and $p<0.01$ was considered as statistically highly significant.

\section{Results}

\section{IGF2-DMRO contains a KLF4 consensus motif}

A hypomethylation of the human IGF2-DMR0 has been shown to be associated with breast, colorectal and esophageal squamous cell carcinoma [23, 41, 42]. By using the JASPAR CORE database [43], which contained 138 matrices and a subset of TRANSFAC release 10.4 (506 matrices of human and mouse origin), we identified in IGF2-DMR0 a putative binding site for the transcription factor KLF4 (Fig. 1). The consensus sequence for KLF4 with the motif 5' -CGGCGTGGC-3' (complementary sequence 3 '-GCCACGCCG-5') possessed a calculated z-score of 7.6 and is located within a region exhibiting a high CpG-density (Fig. 1).

\section{Prostate cancer associates with decreased IGF2 expression and hypomethylation of IGF2-DMR0}

Tissue samples obtained from TUR-BPH $(n=12)$, RP-BPH $(n=43)$ and RP-PCa $(n=69)$ were analyzed and compared with regard to IGF2-mRNA expression. The TUR-BPH samples showed the highest IGF2 expression and were followed by RP-BPH and RP-PCa (TUR-BPH vs. RP-BPH: $p=0.016$; RP-BPH vs. RP-PCa: $p=0.0026$, Mann-Whitney $\mathrm{U}$ test) (Fig. 2a). DNA methylation analyses in IGF2-DMR0 revealed that RP$\mathrm{BPH}$ and RP-PCa samples are significantly hypomethylated when comparing to TUR-BPH samples (TUR-BPH vs. RP-BPH: $p=0.044$; TUR-BPH vs. RP-PCa: $p=0.026$, Mann-Whitney U test). Noticeably, the RP-PCa samples displayed the highest variance of IGF2-DMR0 methylation in both directions (hypo- and hypermethylation; median 44\%, range 4-60\%) (Fig. 2b). In contrast, the methylation of IGF2/H19-ICR (imprinting control region with a CTCF binding site located between IGF2 and H19 genes, Fig. 1) was not significantly different between the prostate cancer groups TUR-BPH, RP-BPH and RP-PCa (Fig. 2c). The highest variance of IGF2/H19-ICR methylation was found in RP-BPH (median 36\%, range 5-78\%) and RP-PCa samples (median 32.5\%, range 7-80\%) (Fig. 2c).

\section{IGF2 LOI in prostate cancer associates with hypermethylation of IGF2/H19-ICR, but not with methylation changes in IGF2-DMRO}

Loss of imprinting (LOI) of IGF2 is considered to be an epigenetic marker for the risk of human cancer, particularly colorectal cancer $[13,44,45]$ and has a potential to affect the gene expression. Although contradictory, some publications also showed an interrelation between IGF2 LOI and methylation changes in IGF2/H19 locus [22, 24]. Here, we aimed to address these issues in prostate cancer. Therefore, we analyzed on cDNAs of 38 selected prostate cancer tissue samples with proven heterozygosity (6 TUR$\mathrm{BPH}, 13 \mathrm{RP}-\mathrm{BPH}$ and $19 \mathrm{RP}-\mathrm{PCa}$ ) the imprinting status of $I G F 2$, i.e. one or two allele expression. The LOI analysis was done by RFLP utilizing the SNP (G/A, ApaI recognition site $\mathrm{GGGCC}^{\wedge} \mathrm{C}$ ) in exon 9 of IGF2 gene (Fig. 1). Among all analyzed G/A heterozygous samples we could identify 9 (1 TUR-BPH, 3 RP-BPH and 5 RP-PCa) with LOI, i.e. bi-allelic expression (Fig. 3a). The remaining 29 samples showed maintenance of imprinting (MOI). Samples with LOI were then compared to those with MOI regarding the IGF2 expression, and no significant difference was found ( $p>0.05$, Mann Whithney U test) (Fig. 3b). We then compared samples with LOI and MOI with regard to DNA methylation in IGF2-DMR0 and in IGF2/H19-ICR. Samples with LOI showed a highly significant increase of IGF2/H19-ICR methylation (median 68\%, range 9-80\%) in comparison to samples with MOI (median 32\%, range $8.77 \%$ ) (LOI vs. MOI: $p=0.007$, Mann-Whitney U test) (Fig. 3d). In contrast, no significant difference between LOI and MOI samples was found regarding the methylation in IGF2-DMR0 (Fig. 3c).

\section{GSTP1 hypermethylation and IGF2-DMR0 hypomethylation} are highly correlated in prostate carcinogenesis

Two previously described tissue markers for prostate cancer, AMACR (alpha-methylacyl-CoA racemase) [46] and GSTP1 (Glutathione S-transferase P1) [47] were analyzed regarding the gene expression $(A M A C R)$ and promoter methylation (GSTP1), respectively, in tissue samples from TUR-BPH, RP-BPH and RP-PCa in order to additionally characterize the used tissue material. As expected, several RP-BPH and RP-PCa samples exhibited very high levels of $A M A C R$ gene expression, but, however, the differences regarding the median expression 


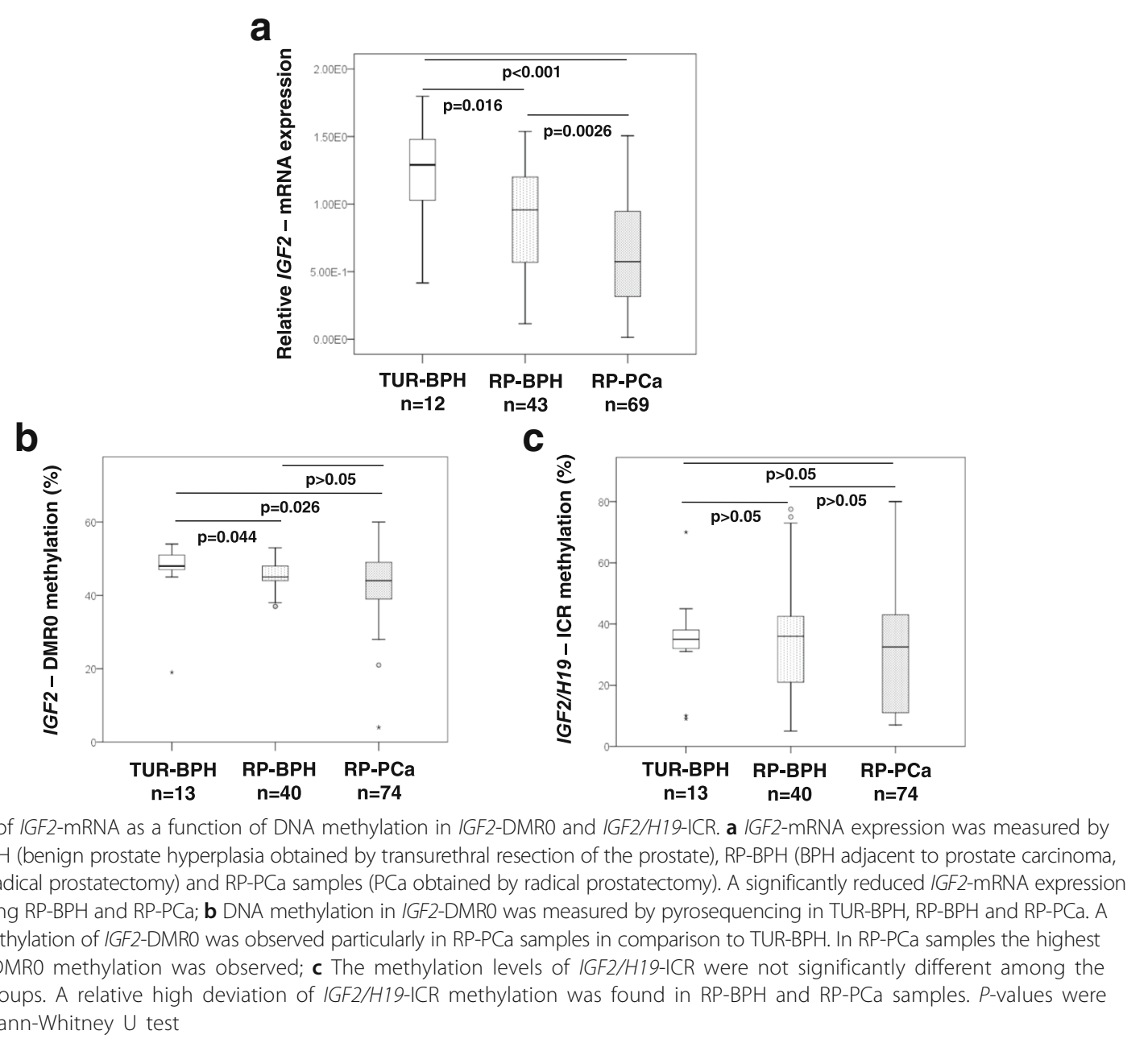

levels of $A M A C R$ were statistically not significant among the analyzed groups (Fig. 4a). In accordance to previous studies, a highly significant increase of GSTP1 promoter methylation was detected in RP-BPH (median 26.6\%, range $0.2-65 \%$ ) and RP-PCa (median 82.5\%, range $2.3-99.9 \%$ ) in comparison to TUR-BPH (median $0.1 \%$, range $0.04-4.9 \%$ ) (TUR-BPH vs. RP-BPH: $p<0.0001$; RP-BPH vs. RP-PCa: $p<0.0001$, Mann-Whitney U test) (Fig. 4b). A significant negative correlation between GSTP1 promoter methylation and IGF2-DMR0 methylation was found when considering all prostate cancer tissues ( $p=0.00032, r=-0.308$, Spearman's rank correlation test) (Fig. 4c). The methylation in GSTP1 promoter was not correlated to the methylation in IGF2/H19-ICR (Fig. 4d).

\section{The majority of prostate tumors exhibit unaltered copy numbers of IGF2 gene}

In the course of carcinogenesis the gain or loss of IGF2 gene copy numbers could be a reason for alterations in gene expression. In order to analyze, if the detected significant reduction of $I G F 2$ expression in RP-BPH and RP-PCa (Fig. 2a) is due to IGF2 copy number changes, we applied a copy number variation (CNV) test. Prostate cancer cell lines PC3, LNCaP and DU145 were analyzed together with three blood DNA samples from healthy donors (controls 1-3) regarding the IGF2 copy numbers using the qBiomarker CNV PCR Assay for Human chromosome 11 tile 10,752 (Qiagen) (Fig. 5a). Among the cell lines, DU145 cells showed a 4-fold increase of IGF2 copies, whereas PC3 and LNCaP showed values similar to those in control samples (Fig. 5a). The IGF2 CNV (gain, loss or normal) was then analyzed in primary prostate cancer tissue samples ( 7 TUR-BPHs, $38 \mathrm{RP}-\mathrm{BPH}$ and 66 RP-PCas). The majority of RP-BPHs (71.1\%) and RP-PCas (66.7\%) exhibited unchanged copy numbers of IGF2. However, in TUR-BPH samples, $28.6 \%$ $(n=2)$ showed gain, 28.6\% $(n=2)$ loss and $42.9 \%$ $(n=3)$ normal copy numbers of IGF2 (Fig. 5b). Samples having gain, loss or normal IGF2 copy numbers were compared with IGF2 expression. By trend, the median expression values for samples with a gain of IGF2 copies 

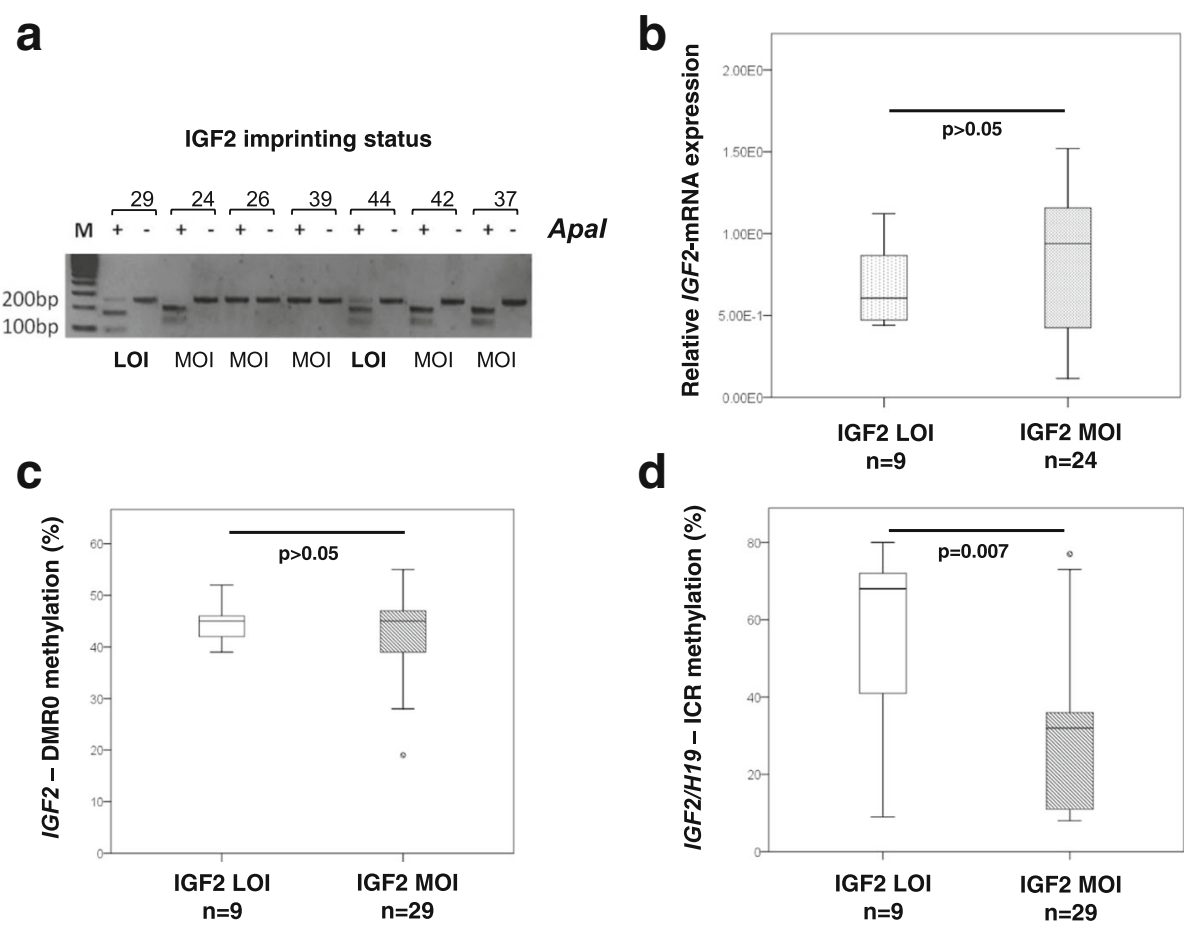

Fig. 3 Association of IGF2 LOI to IGF2 gene expression and DNA methylation in IGF2-DMRO and IGF2/H19-ICR. a /GF2 imprinting status (one or two allele expression) was analyzed by restriction fragment length polymorphism (RFLP, Apal, GGGCC^C) on CDNA generated from tissue samples with heterozygous genotypes. A representative RFLP agarose gel image shows two cases with LOI (loss of imprinting; samples 29 and 44 show bi-allelic IGF2 expression) and five cases with MOI (maintenance of imprinting; samples 24, 26, 39, 42 and 37 show one-allelic IGF2 expression); b No significant difference regarding IGF2-mRNA expression was found between prostate tissue samples exhibiting LOI and MOI; c Methylation of IGF2-DMRO was not significantly changed in samples exhibiting LOI in comparison to those with MOI; $\mathbf{d}$ A significantly higher methylation in /GF2/H19-ICR was found in LOI-group. P-values were determined by Mann-Whitney U test

were higher than for those with normal or decreased copy numbers (Fig. 5c). However, the differences were not significant $(p>0.05$, Mann-Whitney $\mathrm{U}$ test). Moreover, the samples having normal and gained copy numbers also showed often substantially decreased IGF2 expression values (Fig. 5c).

\section{Prostate cancer cell lines LNCaP and DU145 are applicable cell models for epigenetic studies on IGF2-DMRO and its interaction with KLF4}

In order to analyze the binding of KLF4 in IGF2-DMR0 as a function of the methylation status, we analyzed two prostate cancer cell lines LNCaP and DU145, which exhibited an opposite methylation status in IGF2-DMR0 (LNCaP: average 17\% methylation; DU145: 85\%) (Fig. 6a) and expressed the transcription factor KLF4 at mRNA and protein levels (Fig. 6c1 and 2, respectively). For a detailed epigenetic characterization, both cell lines LNCaP and DU145 were then analyzed with regard to post-translational histone modifications (PTHMs) in IGF2-DMR0 (suppressive inactivating marks: H3K9me3 and H3K27me3; active transcription mark: H3K4me3). The hypomethylated IGF2-DMR0 in LNCaP cells (average methylation 17\%) showed an enrichment of
K3K9me3 and H3K27me3, and a depletion of H3K4me3. In contrast, the hypermethylated IGF2-DMR0 in DU145 cells (average methylation 85\%) showed an enrichment of H3K4me3 and a depletion of H3K9me3 and H3K27me3 (Fig. 6b).

\section{KLF4 has a high potential to bind in the hypomethylated IGF2-DMRO and to affect the IGF2 expression}

The binding of KLF4 in the putative KLF4 consensus sequence was analyzed by ChIP in LNCaP and DU145 cells exhibiting different methylation states of IGF2DMR0. A high enrichment of KLF4 was found in LNCaP cells with a hypomethylated IGF2-DMR0 (17\%), whereas in DU145 cells with a hypermethylated IGF2-DMR0 (85\%) KLF4 was absent (Fig. 7a). The cell lines were then treated with a demethylating substance 5-aza-2'deoxycytidin (5-aza, inhibitor of DNMT1) for $72 \mathrm{~h}$. The treatment with 5-aza led to a binding of KLF4 in IGF2-DMR0 in DU145 cells (Fig. 7a). Moreover, the DNA demethylation by 5-aza led to a considerably increase of IGF2-mRNA expression in DU145 cells, whereas in LNCaP cells the IGF2 expression remained at low levels comparable to those detected before 5-aza treatment (Fig. 7b). 

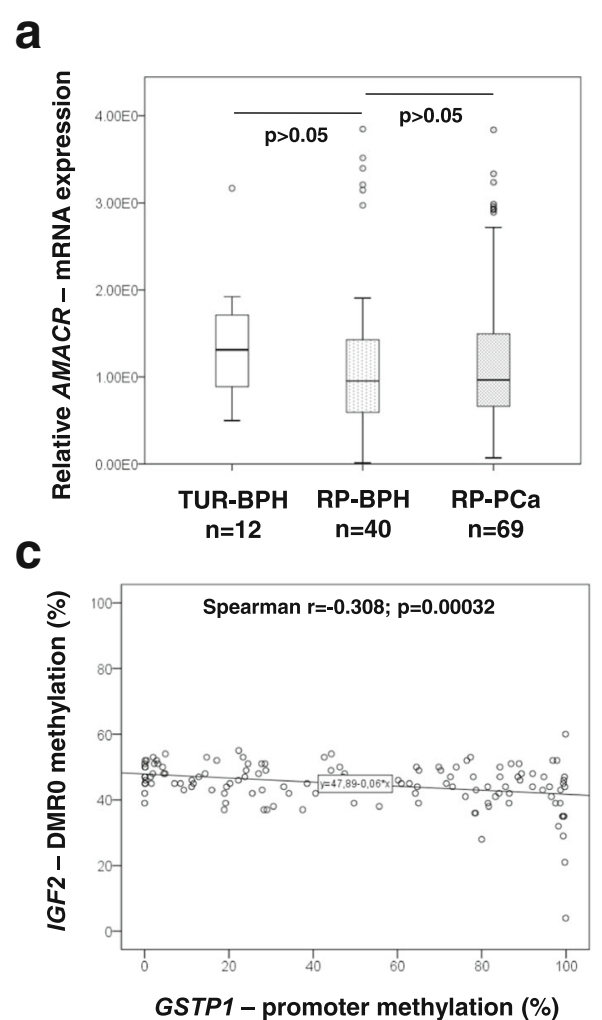

b

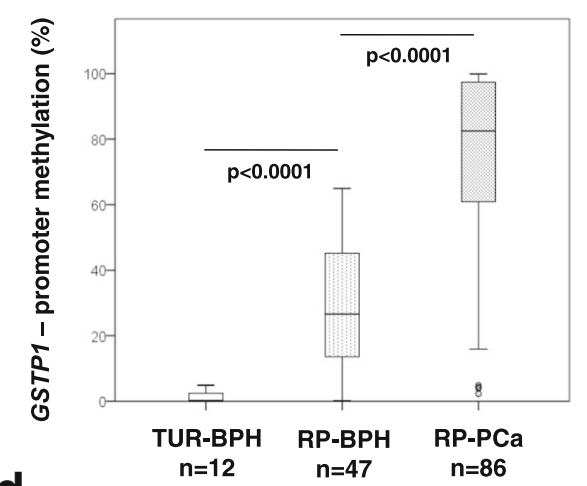

d

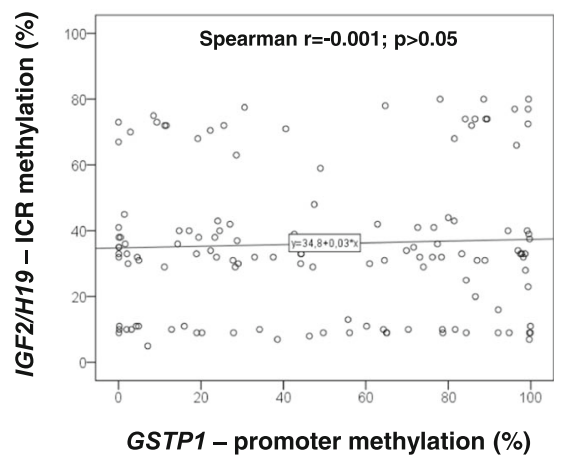

Fig. 4 Studies on prominent biomarkers for prostate carcinogenesis AMACR and GSTP1. a Gene expression analyses of alpha-methylacyl-CoA racemase (AMACR) did not show significant differences between TUR-BPH, RP-BPH and RP-PCa; $\mathbf{b}$ A significantly increased GSTP1 promoter methylation was observed by quantitative methylation specific PCR in RP-BPH and RP-PCa in comparison to TUR-BPH; c The Spearman's correlation test considering all prostate tissue samples revealed a highly significant negative correlation between GSTP1 promoter methylation and IGF2-DMRO methylation; d Methylation levels in IGF2/H19-ICR and in GSTP1 promoter were not correlated. Spearman's rank correlation coefficients $r$ and $p$-values are indicated

Expression of IGF2 gene in prostate cancer is significantly correlated with KLF4 expression

By comparing primary prostate cancer tissue samples grouped in TUR-BPH, RP-BPH and RP-PCa with regard to KLF4 expression, we could not detect obvious differences (Fig. 7c). Tissue samples obtained by radical prostatectomy showed slightly decreased KLF4 expression in comparison to samples obtained by transurethral resection of the prostate and comprised several samples with extreme high levels of KLF4 (Fig. 7c). Interestingly, by considering all prostate tumors together without a separation in TUR-BPH, RP-BPH and RP-PCa, we found a highly significant correlation between KLF4 and IGF2 expression $(p<0.0001$, Spearman's rank correlation coefficient $r=0.668$ ) (Fig. 7d).

\section{Discussion}

Expression of the imprinted gene IGF2 is often dysregulated in human cancer and the molecular mechanisms are still not fully understood. Our current study addressed potential mechanisms leading to transcriptional dysregulation of IGF2 in prostate carcinogenesis.
In this context we analyzed IGF2 expression in prostate tissue obtained by radical prostatectomy ( $\mathrm{RP}-\mathrm{PCa}$ and adjacent $\mathrm{RP}-\mathrm{BPH}$ ) and transurethral prostate resection (TUR-BPH), and correlated it to different cancer associated processes as follows: 1. loss of imprinting (LOI) in $I G F$; 2. DNA methylation changes in the differential methylated region comprising promoter P0 of IGF2 gene (IGF2-DMR0) and in the IGF2/H19 imprinting control region located between $I G F 2$ and $H 19 ; 3$. Gene copy number changes of $I G F 2$. We have also observed the expression of $A M A C R$ and the methylation status of GSTP1 promoter - both proposed tissue markers for prostate cancer. Taking into consideration the experiments performed in prostate cancer cell lines we reveal that hypomethylation of IGF2-DMR0 is a crucial point in deregulation of IGF2 in prostate cancer and that the transcription factor KLF4 is a potent co-factor involved in impairment of IGF2 expression during prostate carcinogenesis.

Loss of imprinting (LOI) in IGF2 and an aberrant IGF2 expression have been reported in human tumors of bladder, esophagus, colon, breast and 

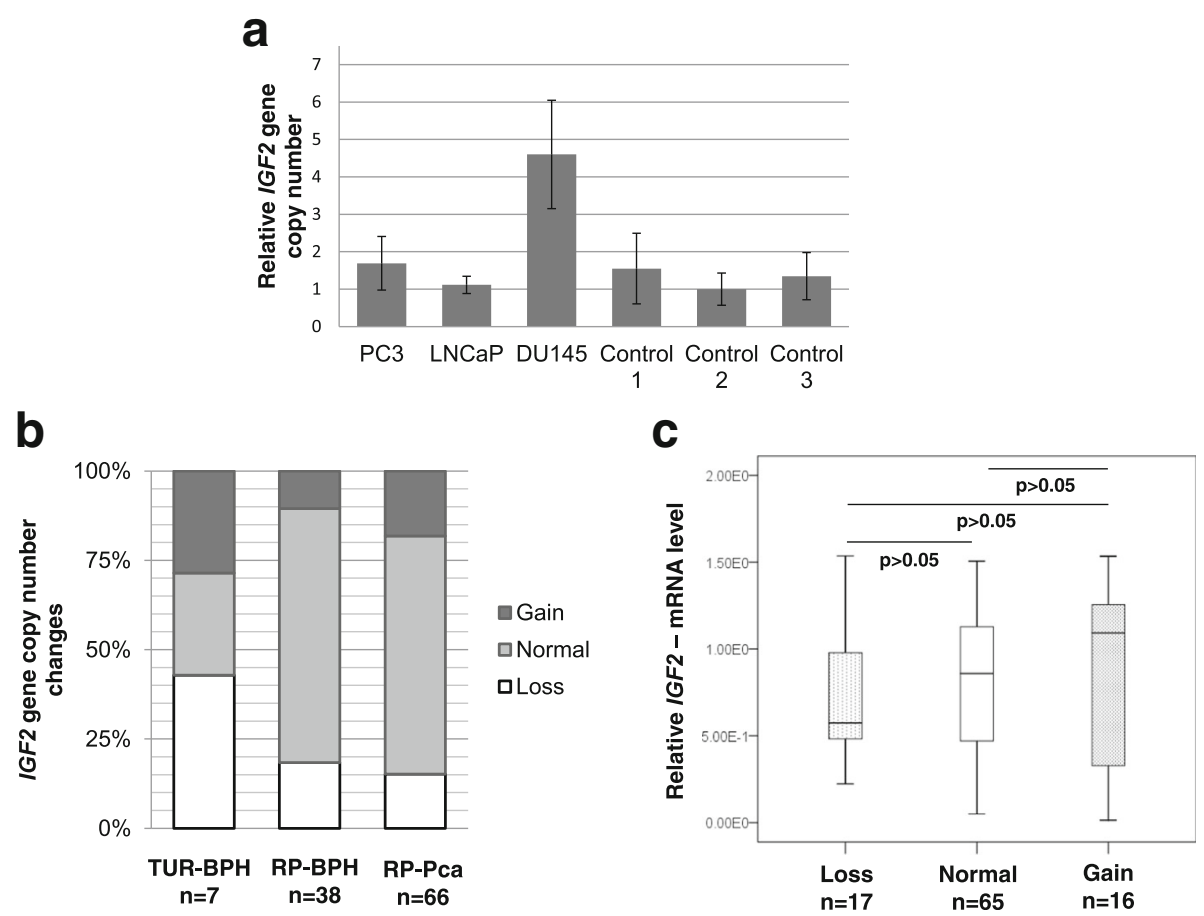

Fig. 5 Analysis of IGF2 gene copy number variation in prostate tumors and association to IGF2-mRNA expression. a Prostate cancer cell lines PC3, LNCaP and DU145 were analyzed together with three blood DNA samples (controls 1-3) regarding the copy number variation (CNV) of IGF2 using the qBiomarker CNV PCR Assay (Qiagen). Increased IGF2 copy numbers were found in DU145 cells, whereas in PC3 and LNCaP the values were comparable to controls. b /GF2 CNV (gain, loss or normal) were analyzed in TUR-BPH $(n=7)$, RP-BPH $(n=38)$ and RP-PCa $(n=66)$. The majority (70\% and 65\%, respectively) of analyzed RP-BPH and RP-PCa samples showed normal copy numbers. c Tissue samples showing decreased, gained or normal copy numbers of IGF2 were grouped and compared regarding IGF2-mRNA expression. No significant differences were found, although by trend, samples having increased IGF2 copies showed higher median IGF2-mRNA values as those with decreased copies

prostate $[16,20,23,42]$. It has been demonstrated that in case of $\mathrm{PCa}$, the tumor-distant and -adjacent tissue samples possess higher IGF2 protein expression than the tumor itself and display also IGF2 LOI [20]. This condition, described for PCa-adjacent and distant tumor-free prostate tissues, has been proposed as a pre-stressing event leading to tumorigenic transformation in long term [20]. Our data confirm the previous observations in prostate cancer and show additionally that not only $\mathrm{BPH}$ samples adjacent to PCa possess significantly higher IGF2 expression as PCa itself, but also $\mathrm{BPH}$ obtained by transurethral prostate resection, i.e. benign prostatic hyperplasia without cancerous cells in the proximities.

Several studies on mouse models as well as human carcinomas demonstrated that altered high levels of IGF2 protein alone are not sufficient to trigger a tumorigenic transformation and that rather IGF2 LOI, a proposed constitutive risk biomarker for colorectal cancer [12, 13, 44, 45], and IGF2-DMR0 hypomethylation seem to be indicative for tumor susceptibility $[15,16,48]$. In our study, most of the cases exhibiting IGF2 LOI (8 out of 9 evaluated LOI) were detected in PCa and in PCaadjacent $\mathrm{BPH}$. The majority of heterozygous prostate cancer tissue samples, suitable for LOI studies (29 out of 38 ), exhibited maintenance of IGF2 imprinting. We found that IGF2 LOI in prostate cancer is not associated with methylation status in IGF2-DMR0, but associates significantly to hypermethylation of the imprinting control region (IGF2/H19-ICR) located between IGF2 and $H 19$ genes.

In terms of IGF2-DMR0, it is known that this locus represents one of the two parentally imprinted regions within the IGF2 gene (DMR0 and DMR2 in exon 9). IGF2-DMR0 possessing promoter activities, is normally hypermethylated at the active paternal allele and was shown to acquire somatically a hypomethylated state in human cancer [19, 22, 23, 41, 42]. In accordance with other publications, we observed a hypomethylation of IGF2-DMR0 in $\mathrm{PCa}$ and in $\mathrm{PCa}$-adjacent $\mathrm{BPH}$, which was significantly different to non-cancerous $\mathrm{BPH}$ obtained by transurethral resection. In contrast, methylation in IGF2/H19-ICR was not significantly changed in the course of prostate carcinogenesis.

In carcinogenesis, the gain or loss of IGF2 gene copy numbers (copy number variation, $\mathrm{CNV}$ ) could be a reason for aberrant gene expression levels. In order to address this issue we examined IGF2 mRNA levels in 


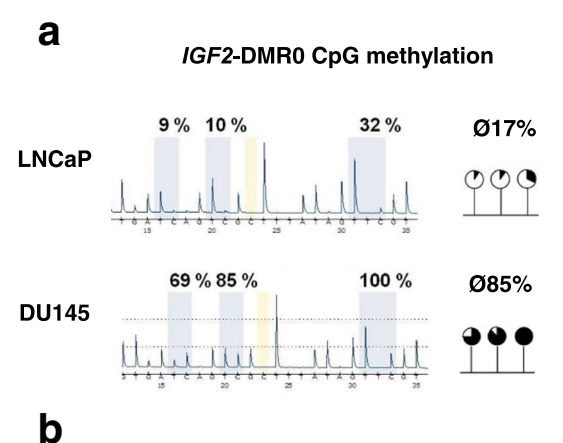

b

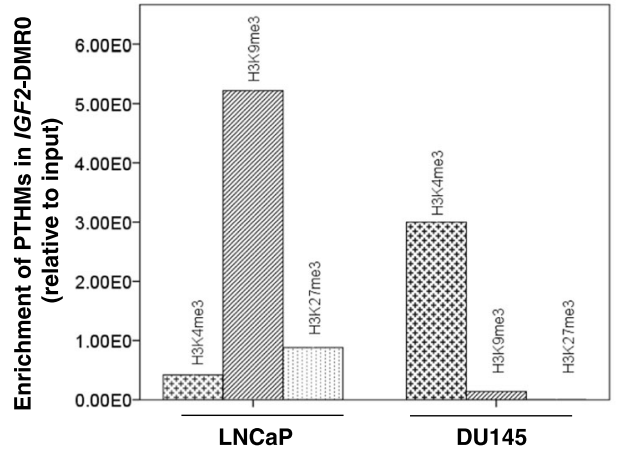

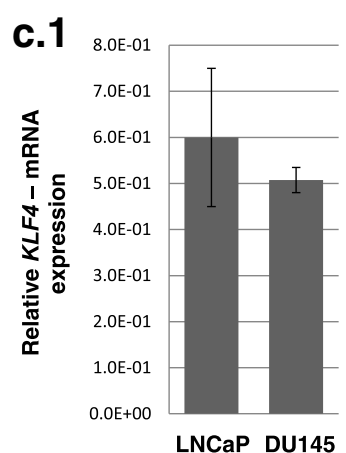

c.2

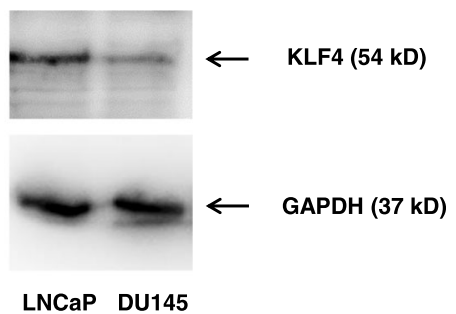

Fig. 6 Epigenetic status of IGF2-DMRO and expression of KLF4 in prostate cancer cell lines LNCaP and DU145. a Pyrograms show that LNCaP cells are hypomethylated in IGF2-DMRO (average 17\%), whereas DU145 cells are hypermethylated (average 85\%); b Analysis of post-translational histone modification (PTHMs) by chromatin immunoprecipitation revealed an enrichment of H3K9me3 and H3K27me3 and a depletion of H3K4me3 in IGF2-DMRO of LNCaP cells. In contrast, in DU145 cells an enrichment of H3K4me3 and a depletion of H3K9me and H3K27me3 was found; c Expression of KLF4 was confirmed in LNCaP and DU145 at mRNA level by RT-qPCR (c.1) and at protein level by western blot (c.2, GAPDH was used as control protein)

prostate tissue samples exhibiting gain, loss and normal copy numbers of IGF2. The samples having gained IGF2 copies exhibited the highest median values for IGF2 mRNA, and those with a loss - the lowest. The differences between the groups were not statistically significant, and moreover, several tumor samples with increased copy numbers exhibited low IGF2 mRNA and, vice versa, several samples with decreased copy numbers possessed high levels of IGF2 mRNA. Thus, $\mathrm{CNV}$ cannot per se explain aberrant IGF2 expression in prostate tumors.

Further, we observed a significant inverse correlation between IGF2-DMR0 and GSTP1 promoter methylation $(r=-308, p=0.00032)$. Hypermethylation of GSTP1 promoter is a hallmark of prostate carcinoma [47] and high methylation rates were associated with more aggressive tumor stages with a Gleason score $\geq 4+3$ [49]. The fact that IGF2-DMR0 hypomethylation goes along with GSTP1 hypermethylation suggests that IGF2-DMR0 hypomethylation could be also considered for risk assessments of prostate cancer. However, GSTP1 methylation was not correlated to methylation in IGF2/H19-ICR.

In order to determine potential co-factors for regulation of IGF2 expression, we analyzed the IGF2-
DMR0 region with regard to putative binding sites for transcription factors and revealed a consensus motif for KLF4. The transcription factor KLF4 belongs to a subgroup of zinc finger proteins and was shown to bind to G/C-rich DNA. Interestingly, hypomethylation of three specific CpGs within the IGF2-DMR0, two of which belong to our identified and analyzed KLF4 consensus sequence, was shown to be closely linked to IGF2 LOI in human tumorigenic tissues of breast, colon and esophagus [23, 42]. Our study revealed that KLF4 binds to IGF2-DMR0 in dependence to the prevailing epigenetic status and affects IGF2 gene expression. Utilizing prostate cancer cell lines, we found in LNCaP that KLF4 binds to hypomethylated IGF2DMR0 and co-localizes with H3K27me3 and H3K9me3. No binding was detectable in DU145, when IGF2-DMR0 was hypermethylated and enriched with H3K4me3. Treatment of DU145 cells with the demethylating substance 5-aza-2-'deoxycytidin led to a 4-fold increase of IGF2 expression. A recent study demonstrated that repression of the maternal IGF2 allele, which is normally unmethylated, is achieved by binding of PRC2 (polycomb repressive complex) components H3K27me3 and H3K9me3 to IGF2-DMR0 [50, 51]. Our results suggest that KLF4 could be involved in 

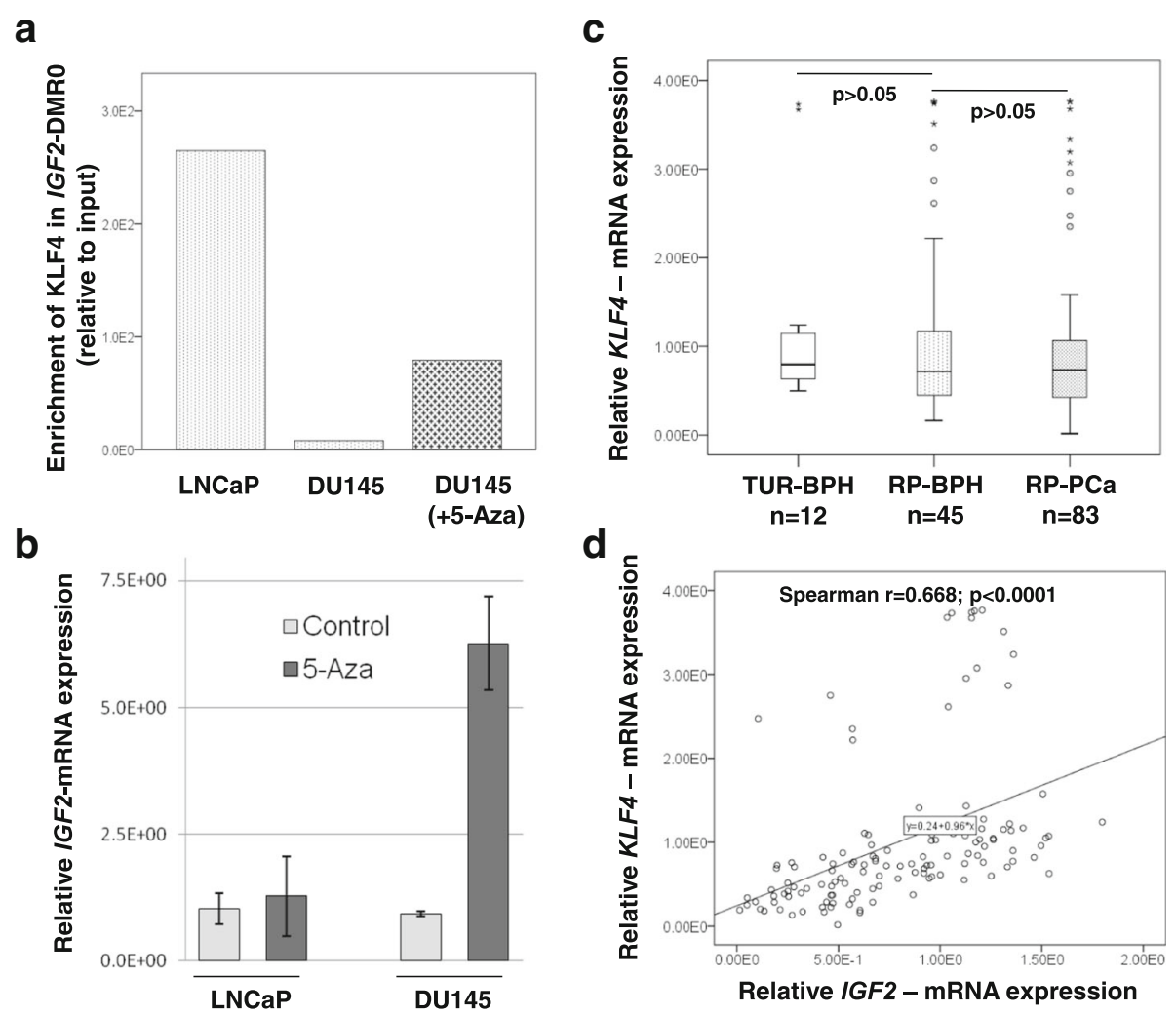

Fig. 7 Enrichment of KLF4 in IGF2-DMRO depends on IGF2-DMRO methylation and affects the IGF2-mRNA expression. a Chromatin immunoprcipitation analyses revealed a high enrichment of KLF4 in IGF2-DMRO in LNCaP cells (17\% methylated in IGF2-DMRO) and low enrichment in DU145 cells (85\% methylated in IGF2-DMRO). Treatment of DU145 cells with 5-Aza (DU145 + 5-aza) led to an increase of KLF4 binding in /GF2-DMRO. b Untreated (control) prostate cancer cell lines LNCaP and DU145 showed similar low levels of IGF2 expression. Treatment with DNA methyltransferase inhibitor 5-aza-2'-deoxycytidin (5-Aza) caused a strong increase of IGF2-mRNA expression in DU145 cells, whereas LNCaP cells were unaffected. c Prostate tissue samples from TUR-BPH, RP-BPH and RP-PCa were analyzed regarding the KLF4-mRNA expression. No significant differences were found between the groups. $\mathbf{d}$ A highly significant positive correlation between KLF4 and IGF2 expression (Spearman's rank correlation coefficient $r=0.668, p<0.0001$ ) was found, when all analyzed primary tumors were considered together without splitting in separate groups

repression of the maternal IGF2 allele. The epigenetic imbalance in IGF2-DMR0 and the ability of KLF4 to bind here and to affect IGF2 expression should be investigated in further studies in more detail with regard to other PRC2 components and to functional consequences.

In terms of prostate carcinogenesis, inhibition of the KLF4/P13/Akt/p21 pathway by microRNA-7 repressed the stem cell attributes of PCa cells and their tumorigenic potential [52]. Furthermore, KLF4 has been reported to mediate lysophosphatidic-acid stimulated migration and proliferation of PC3 cells [53] and to be associated with proliferative activity of $\mathrm{PCa}$ cells through the KLF4-KRT6/13 pathway [38]. However, an earlier study in prostate cancer cell lines, where a RNA- and vector-mediated KLF4 overexpression was achieved, suggested that KLF4 can also act in a tumor suppressive manner [54]. In primary prostate tumors, examinations on tissue samples from age matched patients by immunohistochemistry showed that KLF4 protein is expressed in the vast majority of epithelial cells in BPH as well as in PCa, whereby PCa exhibited lower KLF4 expression as $\mathrm{BPH}$ [37]. Non-tumorous areas of the prostate exhbited at both, mRNA and protein levels, a KLF4 expression similar to $\mathrm{BPH}[36,55]$. Our analyses in prostate tissue samples revealed at the mRNA level that KLF4 expression is slightly decreased in RP-PCa in comparison to RP-BPH and TUR-BPH. However, the differences were not statistically significant, and some samples, particularly in RP-PCa and RP-BPH group, possessed also very high levels of KLF4 expression. What is striking is the fact that, when considering all tumor samples together without separation in groups, we find a highly significant correlation of KLF4 and IGF2 expression $(p<0.0001$, Spearman's rank correlation coefficient $r=0.668$ ). The latter indicates that within a same prostate tumor tissue the IGF2 expression is interconnected to the KLF4 expression. 


\section{Conclusions}

In conclusion, our analyses reveal a potent role of KLF4 transcription regulation on IGF2 in prostate cancer. We demonstrate that, in addition to the DNA methylation degree, the prevailing histone-modifications in IGF2DMR0 are critical for KLF4 binding and IGF2 up- or down-regulation, respectively. Our clinical studies show that the majority of $\mathrm{PCa}$ and adjacent $\mathrm{BPH}$, but not $\mathrm{BPH}$ obtained by TUR, possess severely reduced IGF2 expression and hypomethylated IGF2-DMR0. Expression levels of IGF2 and KLF4 were highly correlated in the different prostate tissues. Moreover, we reveal a significant correlation of GSTP1 hypermethylation and IGF2-DMR0 hypomethylation suggesting the latter as a conceivable biomarker for prostate carcinogenesis. IGF2 LOI and $\mathrm{CNV}$ occurring in the course of prostate tumorigenesis seem not to be the decisive factors for aberrant IGF2 expression. Collectively, our study provides novel insights into IGF2 deregulation mechanisms as a critical process in prostate tumorigenesis.

\section{Abbreviations \\ AMACR: Alpha-methylacyl-CoA racemase; $\mathrm{BPH}$ : Benign prostate hyperplasia; ChIP: Chromatin-immunoprecipitation; CNV: Copy number variation; CTCF: CCCTC-binding factor; GAPDH: Glyceraldehyde 3-phosphate dehydrogenase; GSTP1: Glutathion S-Transferase P1; IGF2: Insulin-like growth factor 2; IGF2/H19-ICR: Imprinting control region regulating parental allele expression of IGF2 and H19 genes; IGF2-DMRO: Differential methylated region in promoter 0 of the IGF2 gene; KLF4: Kruppel-like factor 4; LOI: Loss of imprinting; MOI: maintenance of imprinting; PCa: Prostate carcinoma; PTHM: Post-translational histone modification; RP-BPH: BPH obtained by radical prostatectomy; RP-PCa: PCa obtained by radical prostatectomy; RT-qPCR: Reverse transcription followed by quantitative polymerase chain reaction; TUR-BPH: BPH obtained by transurethral resection of the prostate}

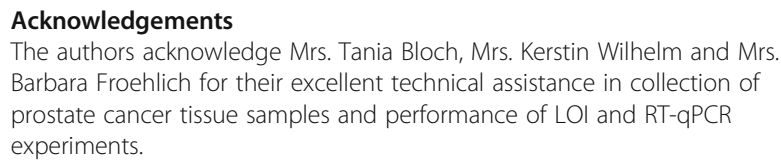

\section{Funding}

This work was supported by the German Cancer Aid (AZ108629, Project "Epigenetic regulation of IGF2/H19 imprinting in prostate cancer").

\section{Availability of data and materials}

The datasets supporting the conclusions of this article are included within the article.

\section{Authors' contributions}

TD and US designed the study. US and KS obtained funding. AL, NS, US and TD performed the experiments. FW provided clinical samples. DS and SG examined and appraised the tumor tissue samples. TD and US analyzed the data and wrote the paper. All authors reviewed and approved the manuscript.

\section{Ethics approval and consent to participate}

All the tissues were obtained from the Clinic of Urology, Pediatric Urology and Andrology, Justus-Liebig-University Giessen. The study was approved by the ethical committee of the Medical Faculty, Justus-Liebig-University Giessen (ethical vote, AZ123/12). All patients gave their written informed consent. The informed consent was obtained from the patients before surgery.
Consent for publication

Not applicalble.

\section{Competing interests}

The authors declare that they have no competing interests.

\section{Publisher's Note}

Springer Nature remains neutral with regard to jurisdictional claims in published maps and institutional affiliations.

\section{Author details}

${ }^{1}$ Clinic of Urology, Pediatric Urology and Andrology, Justus-Liebig-University Giessen, Rudolf-Buchheim-Str. 7, 35392 Giessen, Germany. ${ }^{2}$ Epigenetics of Urogenital System, Justus-Liebig-University Giessen, Schubertstr. 81, 35392 Giessen, Germany. '3Department of Signal Transduction of Cellular Motility, Internal Medicine V, Justus-Liebig-University Giessen, Aulweg 128, 35392 Giessen, Germany. ${ }^{4}$ Institute of Pathology, Justus-Liebig-University Giessen, Langhansstr. 10, 35392 Giessen, Germany. ${ }^{5}$ Molecular Andrology, Justus-Liebig-University Giessen, Schubertstr. 81, 35392 Giessen, Germany.

Received: 20 July 2017 Accepted: 5 October 2017

Published online: 10 October 2017

\section{References}

1. Baker J, Liu JP, Robertson EJ, Efstratiadis A. Role of insulin-like growth factors in embryonic and postnatal growth. Cell. 1993;75:73-82.

2. Chao W, D'Amore PA. IGF2: epigenetic regulation and role in development and disease. Cytokine Growth Factor Rev. 2008;19:111-20.

3. St-Pierre J, Hivert MF, Perron P, Poirier P, Guay SP, Brisson D, Bouchard L. IGF2 DNA methylation is a modulator of newborn's fetal growth and development. Epigenetics. 2012;7:1125-32.

4. Ekström TJ, Cui H, Li X, Ohlsson R. Promoter-specific IGF2 imprinting status and its plasticity during human liver development. Development. 1995;121:309-16.

5. Begemann M, Zirn B, Santen G, Wirthgen E, Soellner L, Büttel H-M, Schweizer R, van Workum W, Binder G, Eggermann T. Paternally inherited IGF2 mutation and growth restriction. N Engl J Med. 2015;373:349-56.

6. Cohen P, Peehl DM, Baker B, Liu F, Hintz RL, Rosenfeld RG. Insulin-like growth factor axis abnormalities in prostatic stromal cells from patients with benign prostatic hyperplasia. J Clin Endocrinol Metab. 1994;79:1410-5.

7. Li SL, Goko H, ZD X, Kimura G, Sun Y, Kawachi MH, Wilson TG, Wilczynski S, Fujita-Yamaguchi $Y$. Expression of insulin-like growth factor (IGF)-II in human prostate, breast, bladder, and paraganglioma tumors. Cell Tissue Res. 1998; 291(3):469-79.

8. Cardillo MR, Monti S, Di Silverio F, Gentile V, Sciarra F, Toscano V. Insulin-like growth factor (IGF)-I, IGF-II and IGF type I receptor (IGFR-I) expression in prostatic cancer. Anticancer Res. 2003;23:3825-35.

9. VX F, Dobosy JR, Desotelle JA, Almassi N, Ewald JA, Srinivasan R, Berres M, Svaren J, Weindruch R, Jarrard DF. Aging and cancer-related loss of insulinlike growth factor 2 imprinting in the mouse and human prostate. Cancer Res. 2008;68:6797-802.

10. Vu TH, Li T, Nguyen D, Nguyen BT, Yao XM, Hu JF, Hoffman AR. Symmetric and asymmetric DNA methylation in the human IGF2-H19 imprinted region. Genomics. 2000;1;64(2):132-143.

11. McCann AH, Miller N, O'Meara A, Pedersen I, Keogh K, Gorey T, Dervan PA. Biallelic expression of the IGF2 gene in human breast disease. Hum Mol Genet. 1996:5:1123-7.

12. Cui H, Onyango P, Brandenburg S, Wu Y, Hsieh CL, Feinberg AP. Loss of imprinting in colorectal cancer linked to hypomethylation of H19 and IGF2. Cancer Res. 2002;62:6442-6.

13. Cui H, Cruz-Correa M, Giardiello FM, Hutcheon DF, Kafonek DR, Brandenburg S, Wu Y, He X, Powe NR, Feinberg AP. Loss of IGF2 imprinting: a potential marker of colorectal cancer risk. Science. 2003;299(5613):1753-5.

14. Ulaner GA, TH V, Li T, JF H, Yao XM, Yang Y, Gorlick R, Meyers P, Healey J, Ladanyi M, Hoffman AR. Loss of imprinting of IGF2 and H19 in osteosarcoma is accompanied by reciprocal methylation changes of a CTCF-binding site. Hum Mol Genet. 2003;12:535-49.

15. Murphy SK, Huang Z, Wen Y, Spillman MA, Whitaker RS, Simel LR, Nichols TD, Marks JR, Berchuck A. Frequent IGF2/H19 domain epigenetic alterations and elevated IGF2 expression in epithelial ovarian cancer. Mol Cancer Res. 2006:4:283-92. 
16. Byun HM, Wong HL, Birnstein EA, Wolff EM, Liang G, Yang AS. Examination of IGF2 and H19 loss of imprinting in bladder cancer. Cancer Res. 2007;67:10753-8.

17. Jelinic P, Shaw P. Loss of imprinting and cancer. J Pathol. 2007;211:261-8.

18. Zhao R, DeCoteau JF, Geyer CR, Gao M, Cui H, Casson AG. Loss of imprinting of the insulin-like growth factor II (IGF2) gene in esophageal normal and adenocarcinoma tissues. Carcinogenesis. 2009;30:2117-22.

19. TH V, Nguyen AH, Hoffman AR. Loss of IGF2 imprinting is associated with abrogation of long-range intra-chromosomal interactions in human cancer cells. Hum Mol Genet. 2010;19:901-19.

20. Bhusari S, Yang B, Kueck J, Huang W, Jarrard DF. Insulin-like growth factor-2 (IGF2) loss of imprinting marks a field defect within human prostates containing cancer. Prostate. 2011;71:1621-30.

21. Leick MB, Shoff CJ, Wang EC, Congress JL, Gallicano GI. Loss of imprinting of IGF2 and the epigenetic progenitor model of cancer. Am J Stem Cells. 2011;1(1):59-74.

22. Murrell A, Ito Y, Verde G, Huddleston J, Woodfine K, Silengo MC, Spreafico F, Perotti D, De Crescenzo A, Sparago A, Cerrato F, Riccio A. Distinct methylation changes at the IGF2-H19 locus in congenital growth disorders and cancer. PLoS One. 2008;3:e1849.

23. Ito $Y$, Koessler T, Ibrahim AE, Rai S, Vowler SL, Abu-Amero S, Silva AL, Maia AT, Huddleston JE, Uribe-Lewis S, Woodfine K, Jagodic M, Nativio R, Dunning A, Moore G, Klenova E, Bingham S, Pharoah PD, Brenton JD, Beck S, Sandhu MS, Murrell A. Somatically acquired hypomethylation of IGF2 in breast and colorectal cancer. Hum Mol Genet. 2008;17:2633-43.

24. Sullivan MJ, Taniguchi T, Jhee A, Kerr N, Reeve AE. Relaxation of IGF2 imprinting in Wilms tumours associated with specific changes in IGF2 methylation. Oncogene. 1999;18:7527-34.

25. Monk D, Sanches R, Arnaud P, Apostolidou S, Hills FA, Abu-Amero S, Murrell A, Friess H, Reik W, Stanier P, Constancia M, Moore GE. Imprinting of IGF2 PO transcript and novel alternatively spliced INS-IGF2 isoforms show differences between mouse and human. Hum Mol Genet 2006;15:1259-1269.

26. Xu W, Fan H, He X, Zhang J, Xie W. LOI of IGF2 is associated with esophageal cancer and linked to methylation status of IGF2 DMR. J Exp Clin Cancer Res. 2006;25:543-7.

27. Suske G. The sp-family of transcription factors. Gene. 1999;238:291-300.

28. Evans PM, Liu C. Roles of Krupel-like factor 4 in normal homeostasis, cancer and stem cells. Acta Biochim Biophys Sin Shanghai. 2008;40:554-64.

29. Rowland BD, Peeper DS. KLF4, p21 and context-dependent opposing forces in cancer. Nat Rev Cancer. 2006;6:11-23.

30. Rouhi A, Frohling S. Deregulation of the CDX2-KLF4 axis in acute myeloid leukemia and colon cancer. Oncotarget. 2013;4:174-5.

31. Huang Y, Chen J, Lu C, Han J, Wang G, Song C, Zhu S, Wang C, Li G, Kang J, Wang J. HDAC1 and Klf4 interplay critically regulates human myeloid leukemia cell proliferation. Cell Death Dis. 2014;5:e1491.

32. Zhao W, Hisamuddin IM, Nandan MO, Babbin BA, Lamb NE, Yang WW. Identification of Krüppel-like factor 4 as a potential tumor suppressor gene in colorectal cancer. Oncogene. 2004;23(2):395-402.

33. Hu W, Hofstetter WL, Li H, Zhou Y, He Y, Pataer A, Wang L, Xie K, Swisher SG, Fang B. Putative tumor-suppressive function of Kruppel-like factor 4 in primary lung carcinoma. Clin Cancer Res. 2009;15:5688-95.

34. Foster KW, Frost AR, McKie-Bell P, Lin CY, Engler JA, Grizzle WE, Ruppert JM. Increase of GKLF messenger RNA and protein expression during progression of breast cancer. Cancer Res. 2000;60:6488-95.

35. Chen YJ, CY W, Chang CC, Ma CJ, Li MC, Chen CM. Nuclear Kruppel-like factor 4 expression is associated with human skin squamous cell carcinoma progression and metastasis. Cancer Biol Ther. 2008;7:777-82.

36. Luo J, Dunn T, Ewing C, Sauvageot J, Chen Y, Trent J, Isaacs W. Gene expression signature of benign prostatic hyperplasia revealed by CDNA microarray analysis. Prostate. 2002;51(3):189-200.

37. Le Magnen C, Bubendorf L, Ruiz C, Zlobec I, Bachmann A, Heberer M, Spagnoli GC, Wyler S, Mengus C. KLF4 transcription factor is expressed in the cytoplasm of prostate cancer cells. Eur J Cancer. 2013;49:955-63.

38. Na XY, Liu ZY, Ren PP, Yu R, Shang XS. Long non-coding RNA UCA1 contributes to the progression of prostate cancer and regulates proliferation through KLF4-KRT6/13 signaling pathway. Int J Clin Exp Med. 2015;8:12609-16.

39. Nakayama M, Bennett CJ, Hicks JL, Epstein JI, Platz EA, Nelson WG, De Marzo AM. Hypermethylation of the human glutathione S-transferase-pi gene (GSTP1) CpG island is present in a subset of proliferative inflammatory atrophy lesions but not in normal or hyperplastic epithelium of the prostate: a detailed study using laser-capture microdissection. Am J Pathol. 2003;163:923-33.
40. Hoebeeck J, van der Luijt R, Poppe B, De Smet E, Yigit N, Claes K, Zewald R, de Jong GJ, De Paepe A, Speleman F, Vandesompele J. Rapid detection of VHL exon deletions using real-time quantitative PCR. Lab Investig. 2005;85:24-33.

41. Baba Y, Nosho K, Shima K, Huttenhower C, Tanaka N, Hazra A, Giovannucci $\mathrm{EL}$, Fuchs CS, Ogino S. Hypomethylation of the IGF2 DMR in colorectal tumors, detected by bisulfite pyrosequencing, is associated with poor prognosis. Gastroenterology. 2010;139(6):1855-64.

42. Murata A, Baba Y, Watanabe M, Shigaki H, Miyake K, Ishimoto T, Iwatsuki M, Iwagami S, Yoshida N, Oki E, Morita M, Nakao M, Baba H. IGF2 DMRO methylation, loss of imprinting, and patient prognosis in esophageal squamous cell carcinoma. Ann Surg Oncol. 2014;21(4):1166-74.

43. Mathelier A, Zhao X, Zhang AW, Parcy F, Worsley-Hunt R, Arenillas DJ, Buchman S, Chen CY, Chou A, lenasescu H, Lim J, Shyr C, Tan G, Zhou M, Lenhard B, Sandelin A, Wasserman WW. JASPAR 2014: an extensively expanded and updated open-access database of transcription factor binding profiles. Nucleic Acids Res. 2014;42:D142-7.

44. Kaneda A, Feinberg AP. Loss of imprinting of IGF2: a common epigenetic modifier of intestinal tumor risk. Cancer Res. 2005;65(24):11236-40.

45. Cui H. Loss of imprinting of IGF2 as an epigenetic marker for the risk of human cancer. Dis Markers. 2007;23(1-2):105-12.

46. Jiang N, Zhu S, Chen J, Niu Y, Zhou L. A-methylacyl-CoA racemase (AMACR) and prostate-cancer risk: a meta-analysis of 4,385 participants. PLoS One. 2013:8(10):e74386

47. Meiers I, Shanks JH, Bostwick DG. Glutathione S-transferase pi (GSTP1) hypermethylation in prostate cancer: review 2007. Pathology. 2007:39(3):299-304

48. Holm TM, Jackson-Grusby L, Brambrink T, Yamada Y, Rideout WM 3rd, Jaenisch R. Global loss of imprinting leads to widespread tumorigenesis in adult mice. Cancer Cell. 2005;8:275-85.

49. Zelic R, Fiano V, Zugna D, Grasso C, Delsedime L, Daniele L, Galliano D, Pettersson A, Gillio-Tos A, Merletti F, Richiardi L. Global Hypomethylation (LINE-1) and gene-specific Hypermethylation (GSTP1) on initial negative prostate biopsy as markers of prostate cancer on a Rebiopsy. Clin Cancer Res. 2015;22:984-92.

50. Li T, Chen H, Li W, Cui J, Wang G, Hu X, Hoffman AR, Hu J. Promoter histone H3K27 methylation in the control of IGF2 imprinting in human tumor cell lines. Hum Mol Genet. 2014;23:117-28.

51. Wang H, Ge S, Qian G, Li W, Cui J, Wang G, Hoffman AR, Hu JF. Restoration of IGF2 imprinting by polycomb repressive complex 2 docking factor SUZ12 in colon cancer cells. Exp Cell Res. 2015;338:214-21.

52. Chang YL, Zhou PJ, Wei L, Li W, Ji Z, Fang YX, Gao WQ. MicroRNA-7 inhibits the stemness of prostate cancer stem-like cells and tumorigenesis by repressing KLF4/PI3K/Akt/p21 pathway. Oncotarget. 2015;6:24017-31.

53. Shin SH, Kwon YW, Heo SC, Jeong GO, Kim BR, Seo EJ, Kim JH. Kruppel-like factor 4 mediates lysophosphatidic acid-stimulated migration and proliferation of PC3M prostate cancer cells. Exp Mol Med. 2014;46:e104.

54. Wang J, Place RF, Huang V, Wang X, Noonan EJ, Magyar CE, Huang J, Li LC. Prognostic value and function of KLF4 in prostate cancer: RNAa and vector-mediated overexpression identify KLF4 as an inhibitor of tumor cell growth and migration. Cancer Res. 2010;70:10182-91.

55. Fujimura T, Takahashi S, Urano T, Takayama K, Sugihara T, Obinata D, Yamada Y, Kumagai J, Kume H, Ouchi Y, Inoue S, Homma Y. Expression of androgen and estrogen signaling components and stem cell markers to predict cancer progression and cancer-specific survival in patients with metastatic prostate cancer. Clin Cancer Res. 2014;20:4625-35.

\section{Submit your next manuscript to BioMed Central and we will help you at every step:}

- We accept pre-submission inquiries

- Our selector tool helps you to find the most relevant journal

- We provide round the clock customer support

- Convenient online submission

- Thorough peer review

- Inclusion in PubMed and all major indexing services

- Maximum visibility for your research

Submit your manuscript at www.biomedcentral.com/submit 